\title{
APROXIMAÇÕES TEÓRICAS SOBRE LINGUAGEM E INTERPRETAÇÃO SOB UMA ÓTICA JURÍDICA E FILOSÓFICA
} \\ Clóvis Gorczevski \\ Universidade de Santa Cruz do Sul - UNISC - Brasil \\ Grazieli Schuch Mayer \\ Universidade de Santa Cruz do Sul - UNISC - Brasil
}

\section{Resumo}

Apresenta-se neste artigo, a partir de uma pesquisa bibliográfica e sob uma ótica jurídica e filosófica, uma reflexão sobre algumas questões envolvendo a essencialidade da linguagem na produção jurídica, na aplicação do direito, passando por autores que muito contribuíram nesta seara do conhecimento, como Gadamer, Habermas, Wittgenstein, entre outros. Bobbio já referia a deficiência da linguagem para a organização social. Diante disso, há que se concluir que a linguagem é essencial para a aplicação do direito, mas não é um mecanismo perfeito, diante da pluralidade de intérpretes e de significados existentes para a mesma norma jurídica, sendo que a hermenêutica filosófica desenvolve um papel fundamental no processo interpretativo. $\mathrm{O}$ artigo que segue procura apresentar elementos críticos ao processo de interpretação jurídica considerando o avanço das teorias clássicas. Propugna-se uma renovação no modo de ser da interpretação jurídica. $O$ avanço adequadamente articulado entre a ontolinguística da teoria hermenêutica e o pragmatismo estrutural da linguística possibilita uma aplicação jurídica pela qual a leitura imprime densidade normativa a princípios e valores jurídicos, sem descambar para a unilateralidade própria da axiologia, do realismo ou mesmo do decisionismo normativista.

Palavras-Chave: Linguagem. Interpretação. Hermenêutica.

\section{Considerações Iniciais}

O Direito, por ser uma ciência interdisciplinar que se comunica, principalmente, com a filosofia, a sociologia, a política, a ética, a linguagem, dentre outras, torna-se um elemento de evolução da própria história de um país. Daí a importância do conhecimento e de toda uma postura dos operadores do direito, como protagonistas deste processo de evolução. 
O objetivo deste artigo é apontar a hermenêutica filosófica contemporânea como a teoria da interpretação em geral e demonstrar sua influência na interpretação do Direito. Para isso, analisar-se-á a função do direito de questionar as normas e a consequente relação com a tradição ético-política. A filosofia, neste aspecto, serve de fio condutor para otimizar o discurso de efetivação dos direitos e, quando constante do movimento da compreensão, realiza a hermenêutica contemporânea.

A estrutura hermenêutico-filosófica possibilita que a compreensão da realidade social, do intérprete e de cada caso concreto seja levantada e analisada durante o processo interpretativo.

Os novos ditames da hermenêutica filosófica ecoaram na hermenêutica jurídica, antes voltada à formulação de regras para uma atividade interpretativa que se exauria na plenitude do ordenamento jurídico, pela simples subsunção dos fatos às normas. O sentido da norma não é mais descoberto, mas construído pela interpretação.

O direito é, quiçá, a disciplina mais expressivamente unida à interpretação, mais mediada e intercedida, em seu labor e seus resultados, por uma constitutiva e permanente atividade hermenêutica. Interpretação é um dos termos mais repetidos e com mais relevante protagonismo, tanto nas obras teóricas sobre o direito, como em sua prática de todo tipo, começando pela jurisprudencial.

No âmbito propriamente jurídico, parece haver poucas dúvidas de que a teoria hermenêutica do direito, influenciada pela recepção de Gadamer, deu passos gigantes no século $\mathrm{XX}$, propiciando uma indubitável aproximação entre momento normativo e momento da decisão prático-concreta, assim como a defesa de uma ontologia jurídica, que vê o direito como um objeto em permanente construção e reconstrução no processo de sua interpretação e aplicação. De fato, muitos e importantíssimos são os problemas levantados e discutidos atualmente no âmbito desta abertura de novos itinerários intelectuais propiciados pelo despertar da consciência hermenêutica dos juristas.

No primeiro tópico abordar-se-ão algumas considerações acerca da hermenêutica jurídica e das teorias unilaterais do direito. Na sequência, serão explorados aspectos relevantes sobre a linguagem, a interpretação e a hermenêutica, passando pelo agir comunicativo de Habermas, para, no terceiro item, analisar a interpretação jurídica sob a ótica da hermenêutica filosófica, apontando os caminhos traçados pela hermenêutica filosófica contemporânea, capitaneada por Gadamer, naquilo que interessa à hermenêutica jurídica em seu estágio atual. 


\section{A hermenêutica jurídica e as teorias unilaterais do direito - breves considerações}

A hermenêutica jurídica consolidou-se sobre uma tradição essencial do direito, qual seja, a de atribuir máxima juridicidade, legitimidade, e mínima arbitrariedade à decisão jurídica, segundo o desígnio do mínimo arbítrio e da máxima realidade jurídica. $O$ exercício hermenêutico se dá justamente para que a determinação do sentido da lei não se realize de modo arbitrário. O intérprete traz a estabilidade da força do texto no momento da aplicação, e não de sua subjetividade, que é apenas passageira, contingente.

Daí que o normativismo, em geral, bem como as teorizações positivista-descritivas posteriores sobre a teoria da linguagem aplicada ao direito, não alcançam a hermenêutica propriamente dita, pois seu estudo exige a análise ontológica da compreensão, pressuposto no ato de ler um texto.

No normativismo, a interpretação jurídica tornou-se um setor incômodo no direito, e não uma característica própria dele, pois o modelo epistemológico de ciência sobre que se funda, promove o abandono do ser, algo próprio da radicalização kantiana do dualismo serdever ser.

A teoria do conhecimento não abrange, pois, o processo de compreensão. No fundo, o preconceito das teorizações dela derivadas está no equívoco de procurar-se um mecanismo descritivo-interpretativo que, pela garantia da neutralidade do método, proporcione uma reposta jurídica exata.

A impossibilidade de erigir um método entre o sujeito que interpreta e o texto a ser interpretado é tangenciada, relegando-se a interpretação jurídica ao decisionismo; à interpretação como ato de vontade do intérprete, atribuindo-se ao órgão oficial pela interpretação uma decisão com caráter discricionário, devido a uma alegada zona de imprecisão linguística própria da regra jurídica.

Haverá pontos em que o direito existente não consegue ditar qualquer decisão que seja correta e, para decidir os casos em que tal ocorra, o juiz deve exercer os poderes de criação do direito. Mas não deve fazer isso de forma arbitrária: isto é, ele deve sempre ter certas razões gerais para justificar a sua decisão e deve agir como um legislador consciencioso agiria, decidindo de acordo com as suas próprias crenças e valores. (HART. 2001, p. 336). 
Isso porque a análise da linguagem pela filosofia analítica desconhece os usos e os diferentes contextos de apropriação. Ao negar-se a contingência do ato hermenêutico, o sentido da lei é relegado à indeterminação.

A interpretação jurídica foi, então, tratada por visões unilaterais do direito. De um lado, tem-se o extremismo do formalismo positivista, segundo o qual a norma deve ser cumprida, pois válida, uma vez que posta por autoridade competente. Essa é a característica do direito como ciência, do direito como direito positivo vigente, que considera, exclusivamente, o aspecto da legalidade, exterior da norma, avalorativamente considerado: a letra, o corpus da lei.

Nisso, o intérprete procura assumir uma atitude neutra diante do direito. "Na distinção entre juízo de fato - tomada de conhecimento da realidade apenas com finalidade de informar, constatar - e juízo de valor (tomada de posição frente à realidade, para influir sobre o outro), este último é excluído do campo científico". (BOBBIO, 1995, P. 135).

Nesse caso, o jurista comporta-se como um cientista, pois analisa o fenômeno jurídico analogamente ao da natureza. A interpretação é algo puramente mecanicista, onde na atividade do jurista prevalece o elemento declarativo sobre o criativo do direito. Objetivamente, a norma jurídica é colocada como objeto, como um dado empírico da natureza. Seu conteúdo é puramente descritivo, e a linguagem atém-se ao sentido imediato.

Não há, nesse caso, qualquer menção à questão da pré-compreensão ou à situação do intérprete. A referência à realidade é desconsiderada, pois a qualificação de bom e mau, justo e injusto, relativo ao conteúdo da norma, comporta um juízo de valor que é negado, para cumprir os postulados de cientificidade. A ideia do justo torna-se irrelevante, pois significa, para o positivismo, um princípio sem validade universal.

Nos estudos de Warat, tem-se que "para o positivismo, há uma concepção formalista de justiça que não leva em conta as influências históricas, políticas e ideológicas na determinação dos conteúdos da norma, ou, ainda, o positivismo, na realidade, reduz a justiça à sua validez". (2004, p. 67).

No outro extremo, tem-se o realismo jurídico. Nele, o direito é considerado uma realidade social na qual as normas são vinculadas à sua eficácia social. "A escola realista do direito pode ser resumida da seguinte maneira: é direito o conjunto de regras que são efetivamente seguidas numa determinada sociedade." (BOBBIO, 1995, p. 142).

Assim, enquanto o positivismo formalista considera o direito uma realidade normativa, abrangendo o plano do dever-ser, o realismo considera-o uma realidade fatual, através do plano do ser. No aspecto das fontes, aquele enfatiza a atividade legislativa e este coloca a 
proeminência na atividade do juiz, ou seja, as normas jurídicas são aquelas efetivamente aplicadas pelos juízes no exercício de suas funções.

As normas legisladas, mas não aplicadas, não são direito. Direito é essencialmente aquilo que as pessoas, empiricamente consideradas numa comunidade, consideram e reconhecem reciprocamente como norma e modo de viver em comum, o que significa uma ética própria do subjetivismo social. Isso sugere um caráter predominantemente sociológico, eis que se orienta por dados imediatos, socioeconômicos, e sobre o efeito das instituições jurídicas. Nesse caso, o direito torna-se um instrumento a serviço de finalidades econômico-sociais.

Tanto o formalismo jurídico-científico quanto o realismo partilham da (pré) compreensão do direito imediatamente considerado, isto é, uma realidade empiricamente constatada, independente de sua processualidade histórica idealmente pressuposta, mediata. Ambos são formais, pois estabelecem o que é direito, prescindindo de seu conteúdo, da matéria regulada. O conhecimento é algo puramente passivo e contemplativo; a interpretação é meramente declarativa ou reprodutiva de um direito preexistente. $\mathrm{O}$ direito é definido como técnica social, ou seja, um instrumento independente de qualquer propósito ou valor, como próprios do fenômeno jurídico. É apenas um mecanismo de controle social, essencialmente coercitivo, para manutenção do status quo.

Como reflexo, a interpretação não é orientada por um elemento teleológico determinado, pois não há a explicitação e o conhecimento de fins, ideais a serem realizados pelo sistema; a ordem jurídica é, eminentemente, um instrumento para garantir e preservar a ordem existente.

Tais visões unilaterais da realidade jurídica distorcem o processo hermenêutico de apreensão de sentido, em prejuízo do plano ontológico da compreensão ou do deôntico vigente.

De um lado, o direito como ciência puramente normativa, que toma a norma em si isolada de sua interpretação, é apenas uma abstração sem efetividade, uma pura forma universal, uma necessidade sem conteúdo. De outro, o direito como ciência do ser - de relações fáticas mutáveis, isoladas de sua determinação deôntica - é pura contingência; uma matéria sem universalidade, confundindo-se com a política e a sociologia; uma prática social sem condicionamento jurídico-normativo.

É preciso superar essas teorias unilaterais do direito e a hermenêutica filosófica contribui decisivamente neste processo. A hermenêutica filosófica permite que o intérprete traga à fala o que compreendeu, numa perspectiva de abertura e de aproximação à realidade, inversamente ao que ocorre na hermenêutica clássica, onde os símbolos suprimem a realidade. No mundo dos fatos, os ideais defendidos pela hermenêutica da compreensão singularizam cada interpretação. 
De acordo com Gadamer:

À medida que a hermenêutica supera a ingenuidade positivista presente no conceito dado, através da reflexão sobre os condicionamentos da compreensão (compreensão prévia, prioridade da pergunta, história da motivação de cada enunciado), ela faz também uma crítica da reflexão metodológica positivista. (2004, p. 133).

Nesse abismo abstrato dogmatizado entre ser e dever-ser, no qual o ser é uma realidade fática vazia de norma e o dever-ser uma norma vazia de realidade fática, a nova hermenêutica, especialmente a filosófica, tornou-se uma alternativa privilegiada para superar tais unilateralidades pela via da interpretação como aplicação.

\section{Linguagem, interpretação e hermenêutica: alguns apontamentos}

As hermenêuticas pós-estruturalistas, definitivamente instaladas na deriva onipresente da linguagem, decidiram cortar as amarras com qualquer forma de realismo ou naturalismo, decretando que o único real é a deriva do significado, uma viagem sem retorno na qual não podem ser precisados nem a origem nem o fim das cadeias significantes, sendo que não existe nenhum vínculo, enlace ou atadura, nem ontológica nem antropológica, senão a exclusiva esfera autoreferente da linguagem.

O problema, contudo, é que a centralidade da linguagem, como ocorre com tantas ideias filosóficas e teorias sociais, como, por exemplo, no desconstrucionismo, no pós-modernismo e em outras doutrinas relativistas e analíticas, é levada a extremos inverossímeis e irrealistas: desde os sofistas, passando por Hobbes e Nietzsche, até desembocar nos textos de oráculos como Derrida, crivados de aforismos como "Não é possível escapar da linguagem", "O texto é autoreferente", "Linguagem é poder" e "Não existe nada fora do texto", ou na afirmação mais extrema de Roland Barthes de que "O homem não existe anteriormente à linguagem, seja como espécie, seja como indivíduo".

Na verdade, só é necessário sentido comum para ver que a língua não poderia funcionar se não se assentasse sobre uma vasta infra-estrutura de conhecimento tácito sobre o mundo e sobre as intenções de outras pessoas, isto é, de que as palavras sempre são interpretadas no contexto de uma compreensão mais profunda das pessoas e suas relações.

No nosso caso, por exemplo, a própria existência de normas ambíguas, nas quais uma série de palavras expressa pelo menos dois pensamentos, prova que pensamentos não são a 
mesma coisa que uma sequência ou classes de palavras, e que estamos equipados com faculdades cognitivas complexas que nos mantêm em contato com a realidade.

A linguagem, assim entendida, é a magnífica faculdade que usamos para transmitir pensamentos e informação de um cérebro para outro, e podemos cooptá-la de muitos modos para ajudar nossos pensamentos a fluir.

Por outro lado, a linguagem não é o mesmo que pensamento, nem a única coisa que separa os humanos dos outros animais, a base de toda cultura, a morada do ser onde reside o homem, uma prisão inescapável, um acordo obrigatório, os limites de nosso mundo ou o determinante do que é imaginável.

Dito de outro modo, a linguagem é simplesmente o conduto através do qual as pessoas compartilham seus pensamentos e intenções, suas experiências de prazer e de sofrimento, enfim, a que permite o reparte sócio-afetivo da subjetividade, e, com isso, adquirem o conhecimento, os costumes e os valores daqueles que as cercam e no contexto da realidade em que plasmam suas respectivas existências.

A importância da interpretação é inequívoca e não precisa ser demonstrada pelo simples fato de sua ligação inseparável a qualquer apreensão de sentido. Ainda mais se o exercício interpretativo se desenvolve no campo do saber jurídico: “Toda lei é obra humana e aplicada por homens; portanto imperfeita na forma e no fundo, e dará duvidosos resultados práticos se não verificarem, com esmero, o sentido e o alcance das suas prescrições” (MAXIMILIANO, 1999, p. 9-10).

A hermenêutica ou teoria da interpretação jurídica desenvolveu-se com o fím de organizar racionalmente o processo de interpretação e aplicação do Direito. A seguir, veremos, brevemente, os caminhos traçados pela hermenêutica filosófica contemporânea, capitaneada por Gadamer, naquilo que interessa à hermenêutica jurídica em seu estágio atual.

Interessante roteiro para um estudo da hermenêutica são as duas faces propostas por SILVA: "como se dá a compreensão e qual a relação entre o sujeito que interpreta e o objeto interpretado; e a busca do(s) método(s) que viabilize(m) a tarefa de interpretar". (2001, p. 126).

Quanto ao primeiro aspecto, Gadamer inaugura nova fase na Hermenêutica, completando o caminho iniciado por Schleiermacher, Dilthey e Heidegger, ao trazer à tona o estudo da experiência humana e sua inserção no mundo como determinantes da compreensão. O foco direciona-se para o exame das condições em que ela ocorre.

Explica SILVA: 
Assim, a partir do século XIX, a hermenêutica sofreu o que ficou conhecido como 'giro hermenêutico': no lugar de investigações em torno do método mais seguro para que se pudesse obter sucesso no conhecimento, a atividade hermenêutica passou a investigar o que efetivamente acontece em todo o processo de compreensão humana, numa perspectiva assumidamente fenomenológica. (2001, p.135).

Presenciou-se uma mudança na antiga visão da dicotomia sujeito/objeto do conhecimento científico: da separação estanque entre o sujeito que interpreta e o objeto interpretado, que seria inerte, passivo, passa-se à acepção de uma influência recíproca, permeada pela historicidade.

Na definição do homem pela existência, Heidegger instituiu o conceito do Dasein ("ser ấ"), aproveitado por Gadamer, que, simplificadamente, pode-se explicar "pela possibilidade da descoberta do ser pela sua própria presença" (GADAMER, 2003, p. 347), a forma como ocorre no mundo, como se manifesta: "o Dasein já é sempre e constitutivamente relação com o mundo, antes de toda a distinção artificial entre sujeito e objeto" (STRECK, 2000, p. 180).

Por estarmos no mundo e pela nossa natureza humana resulta que compreender é uma estrutura do homem e do Dasein, um desdobrar das próprias possibilidades. "Toda compreensão, assim, é uma autocompreensão e quem compreende projeta possibilidades de si mesmo" (DINIZ, 1998, p. 219).

Em razão do seu existir, "quem compreende tem uma prévia compreensão das coisas, ou uma perspectiva de sentido" (LARENZ, 1997, p. 288). "Essa pré-compreensão ou tradição se propaga por meio da linguagem". (GADAMER, 2003, p. 497).

O que é transmitido mostra novos aspectos significativos em face da continuação histórica. "Toda atualização na compreensão pode entender a si mesma como uma possibilidade histórica do compreendido" (STRECK, 2000, p. 192).

Já afirmava LARENZ que "toda a interpretação da lei está, até certo ponto, condicionada pela época" (1997, p. 443). O intérprete é um ser histórico, imerso na sua realidade (consciência histórica):

\footnotetext{
Como se apresenta a seu intérprete, o verdadeiro sentido de um texto não depende do aspecto puramente ocasional representado pelo autor e seu público originário. Ou pelo menos não se esgota nisso, pois sempre é determinado também pela situação histórica do intérprete e, consequentemente, por todo curso objetivo da história (GADAMER, 2003, p. 392).
}

Para Gadamer, "o compreender é histórico porque históricos são a existência do homem e o mundo que o circunda" (SILVA, 2001, p. 139). 
De sua situação pontual no tempo, decorre que o processo de compreensão está vinculado ao passado, presente e, também, futuro (historicidade): “o passado é compreensível por sua efetividade contrastada com o presente e sua faticidade presente o converte em veículo de uma compreensão projetada para o futuro" (DINIZ, 1998, p. 219).

A construção do entendimento ocorre por meio de um processo dialético envolvendo o passado e o presente, que se renova a cada interpretação. "Uma interpretação nunca é definitiva, porque as relações da vida, sempre mutáveis, criam novas questões relevantes para o aplicador do Direito". (LARENZ, 1997, p. 443).

\begin{abstract}
Em ambos os casos [hermenêutica jurídica e teológica] isso implica que, se quisermos compreender adequadamente o texto - lei ou mensagem de salvação -, isto é, compreendê-lo de acordo com as pretensões que o mesmo apresenta, devemos compreendê-lo a cada instante, ou seja, compreendê-lo em cada situação concreta de uma maneira nova e distinta. Aqui, compreender é sempre também aplicar (GADAMER, 2003, p. 408).
\end{abstract}

Assim, dá-se a 'fusão de horizontes': "o horizonte da experiência derivada do momento histórico em que o texto da norma a ser interpretada foi escrito e o da experiência de que faz parte o intérprete. O objetivo da interpretação é uni-los” (DINIZ, 1998, p. 219).

A fusão dos horizontes, como trabalha os horizontes históricos presente e passado, sob a força da tradição transmitida pela linguagem, determina o caráter produtivo, criativo, construtivo da interpretação. Em decorrência da "consciência histórico-efeitual" (STRECK, 2000, p. 194), o intérprete adiciona sentido ao texto interpretado, o que implica a produção de um novo. "A interpretação da lei é uma tarefa criativa” (COELHO, 2003, p. 23).

Nesse sentido, Heidegger e Gadamer trouxeram à construção da hermenêutica filosófica a contribuição produtiva do intérprete no movimento da compreensão, bem como a elevação da linguagem para dentro do processo interpretativo. Também atribuíram ao conhecimento da verdade um sentido ontológico, ao contrário do apego à historicidade, realçado pela hermenêutica clássica.

Esclarece Pereira:

Em Heidegger, a compreensão deixa de ser uma propriedade para se tornar um modo de existência [...] Gadamer, fazendo uso de vários ensinamentos de Heidegger, surge como uma crítica radical ao pensamento científico-espiritual que perdurou por todo o século XIX, fazendo da hermenêutica uma disciplina filosófica que, para além de seu foco epistemológico - presentes nas obras de Schleiermacher e Dilthey -, passa a investigar o fenômeno da compreensão em si mesmo, ou seja, passa a ter como finalidade explicitar o que ocorre nesta operação humana fundamental do compreender. (2001, p. 17). 
De acordo com os ensinamentos de Heidegger houve um salto das questões metodológicas, que, inicialmente, se inspiravam nas ciências e na espiritualidade, para a contribuição e elevação da compreensão no ato de interpretar.

Habermas é considerado um dos mais influentes pensadores da atualidade no que diz respeito à interpretação jurídica e linguagem. Sua obra tem sido muito relevante, porque capitaneia os horizontes filosóficos da universidade e propõe modelos de atuação política concretos na realidade social.

Dois grandes momentos podem ser vislumbrados na filosofia de Habermas:

\begin{abstract}
No primeiro deles, desde a sua formação até o final da década de 1960, embebeu-se do marxismo e do hegelianismo, hauridos do seu contato com os pensadores da Escola de Frankfurt. Num segundo momento, ao se aproximar das correntes de pensamento liberais e pragmáticas dos anglo-saxões, promove uma espécie de virada linguística em suas ideias. É a partir desse momento que seu pensamento se torna presente de modo avassalador no ambiente jurídico ocidental. (MASCARO, 2013, p. 359).
\end{abstract}

Cabe salientar aqui a forte atuação da virada linguística em sede de hermenêutica filosófica, fenômeno que faz da linguagem a interpretação mesma, diversamente da hermenêutica clássica, que relega a linguagem a terceiro elemento. Não há colocação de sentido, mas sim, a aplicação da compreensão, diferentemente da metodologia que relega a linguagem a um resumo de identificação entre sujeito e objeto.

O resultado da virada linguística é a construção da teoria do agir comunicativo. Para Habermas, o fundamento da sociabilidade reside na comunicação. Assim, a tarefa maior da filosofia deve ser direcionada para a questão do entendimento entre os indivíduos e a sociedade. O consenso passa a ser o principal objeto da filosofia de Habermas. O direito, nesse quadro, é a ferramenta maior do consenso.

Habermas se afasta de conceitos metafísicos e defende que "não existe uma verdade absoluta que paira sobre todos, mas existe uma verdade construída enquanto consenso". (1989, p. 120).

Para Habermas, a verdade se constrói enquanto processo comunicacional. Porém, a teoria do agir comunicativo não é apenas uma teoria da linguagem.O principal ponto é a possibilidade de o agir comunicativo gerar consenso.

No conceito de Habermas:

A linguagem nasce da interação pessoal e tende para o consenso e para a racionalidade. $\mathrm{O}$ acordo entre o emissor e o ouvinte é a condição final para que este 
realize os efeitos da emissão. A produção de normas, quer morais, quer jurídicas, decorre da universalização desse consenso". (PUGLIESI, 2005,p. 227-228).

Habermas, ao desenvolver a teoria do agir comunicativo, percebeu que o desenvolvimento isolado de uma racionalidade técnica autônoma, e a consequente validação do direito esgotada na formalização pontuada, ideia de que a legitimidade do direito se verifica na formalização legislativa (como ocorre nas teorias de Kelsen e Hart), não alcançava qualquer projeto de justiça, pois firmada unicamente no tecnicismo jurídico desconectado das considerações morais e ético-políticas. Habermas então defende uma interação do direito com a sociedade, como forma de alcançar o melhor convívio social.

Dessa forma, a racionalidade se apresenta como abertura do consenso. Habermas aposta em mais direito, numa interação democrática e ética do direito com a sociedade, como forma de alcançar o melhor, driblando os conflitos do mundo a partir do consenso.

\section{A interpretação jurídica sob a ótica da hermenêutica filosófica}

A hermenêutica contemporânea tem em Nietzsche e em Heidegger seus genuínos fundadores. Eles, além de outros autores, traçaram os caminhos de seu discorrer e são, de fato, o ponto de referência das diferentes hermenêuticas: desde o caráter ontológico-universal da hermenêutica de Gadamer, cuja filiação e procedência heideggeriana é manifesta, até a "hermenêutica niilista" de Gianni Vattimo, para quem só remetendo-se a Nietzsche e a Heidegger a hermenêutica adquirirá o peso e transcendência filosóficos que lhe são próprios, passando pela hermenêutica crítica de Ricouer, que vê na ontologia hermenêutica nietzscheana o melhor adversário com quem seu pensamento tem de se medir, e em Heidegger o lugar de passagem iniludível.

A filosofia hermenêutica procura abordar o texto pela sua atualização de sentido, segundo o momento da aplicação, através de um processo interpretativo decorrente da apropriação da totalidade de sentido imanente ao texto. Esse ato se dá pela fusão entre a subjetividade do intérprete e a objetividade sistemática do texto.

O texto aqui, tomado isoladamente do intérprete, é uma abstração sem realidade, como portador de um significado apenas potencial. Como abstração, a norma é uma significação analítica sem evento, sem acontecimento. O sentido normativo é determinado pela dialética entre a significação imanente do discurso inscrito e o evento de sua compreensão, segundo o movimento de apropriação, da dialética destes dois momentos. Na verdade, norma e texto são 
inseparáveis, fazendo parte de um mesmo evento do sentido, mas este, no caso, transcende a pura imanência do texto.

Apesar de propor o movimento de desregionalização, a incorporação da hermenêutica filosófica no âmbito jurídico, como hermenêutica jurídica, impõe uma especialização em relação às demais hermenêuticas, pela necessidade prática de oposição entre o caráter abstrato do sentido imanente da norma jurídica e a exigência de justiça na particularidade do fato empírico oposto no momento do evento da compreensão.

O direito impõe, portanto, a consideração de outros elementos tangenciados pela filosofia hermenêutica, particularmente, da necessidade de aplicação justa de seu texto. "O justo qualifica, em última instância, uma decisão singular tomada em um clima de conflito e de incerteza." (MAGALHÃES, 2002, p. 112).

Assim, além de determinar o significado do texto normativo, há ainda a tarefa complementar, de aplicá-lo com equidade, considerando o seu valor e aplicabilidade diante do caso concreto. Daí ser necessária a diferenciação, no âmbito jurídico, mesmo que fundidos filosoficamente, entre interpretação, como momento intelectivo do processo de aplicação, e a aplicação propriamente dita, que o supera para incluir o momento volitivo, na questão prática da decisão.

A hermenêutica jurídica dá-se por meio do ato de interpretação do fato e da norma. Como ato, é um processo dinâmico, caracterizado pela ação. É um acontecimento realizado dialeticamente como a apropriação do texto na norma efetiva do caso concreto. É a negação da generalidade e abstração da norma pela oposição à particularidade empírica do caso concreto, ou seja, a determinação singular de sentido para cada caso, a partir da significação imanente da norma.

O intérprete, aplicador, aqui, é o elemento mediador entre a tendência generalizadora da significação normativa a priori, pela qual, todos são formalmente iguais perante a lei, o que é próprio da abstração de um estado de sistema, e a tendência individualizadora da necessidade de justiça no caso concreto, obedecendo a um processo de adequação valorativa para alcançarse o justo: a igualdade na lei.

Assim, o intérprete é um elemento ativo da interpretação sob um duplo aspecto. Além de determinar o sentido da norma pela interpretação, é um fator ativo de concretização do preceito abstrato ao caso concreto, pois canaliza, valorativamente, dentro da variedade significativa de um estado de sistema, aquele significado que se ajuste como próprio ao caso concreto.

Neste sentido, afirma Saldanha que: 
O sujeito é sempre ativo (activus), o ato é sua realidade específica, e o fato de ele ser sujeito do pensar e do compreender não desmente sua condição de sujeito do agir e do fazer [...] Ao atuar, dentro dos contextos e dos momentos, o sujeito (cela vasansdire) assume valores e cumpre opções. Ao conhecer seus próprios atos, o sujeito nivela a sua consciência com sua existência." (2003, p. 224).

A tarefa de interpretar é criativa de atribuição de sentido e não de criação do direito, pois não se trata de uma invenção de sentido pelo intérprete, o que seria a desvinculação à legislação, mas de "descoberta do direito que existe já em estado latente no sistema positivo". (FERRARA, 1987, p. 171).Representa, nesse aspecto, uma tarefa contínua de aplicação do texto, tendo em vista a recontextualização, atualização de seu sentido objetivo.

O texto, no âmbito jurídico, não é um enunciado linguístico separado de sua normatividade, mas um elemento do direito positivo em ação que revela, pela sua atualização por meio da interpretação, os valores constitutivos do direito vigente. O texto, segundo o modelo hermenêutico, não é, propriamente, algo separado da norma, como se a norma fosse mero resultado do método usado na interpretação, mas constitutivo do evento da compreensão, quando se atualiza seu sentido, tendo em vista a situação do intérprete.

O sentido extraído do texto não é, ontologicamente, algo formal, mas determinado axiologicamente como seu modo de ser pelo evento da compreensão. "Não se trata, pois, de uma forma de normativismo, no qual a norma precede o valor, nem uma forma de axiologia, na qual o valor precede a norma”. (SALGADO, 2006, p. 7).

A tarefa do intérprete é justamente a formação do sistema pela interpretação textual, ou seja, a contínua apropriação e revelação de seu sentido axiológico pela unidade do processo hermenêutico.

Neste sentido:

Toda tarefa e esforço, tanto do legislador como do julgador, é descobrir o direito como ordem de valores de uma cultura. Mas é ao Judiciário que cabe revelar o direito contido na norma legal, veiculando a realidade social e cultural do momento da aplicação da norma, com o sentido axiológico dessa norma. Se o Legislativo põe abstratamente modelos de conduta que possibilitam a realização do direito, é o Judiciário que restabelece o direito lesado, extraindo-o das formas abstratas das leis da matéria concreta das relações da vida onde quase todo o direito se realiza, dia a dia, independentemente da coação em ato do Estado. (SALGADO Apud MERLE, Jean C.; MOREIRA, Luis (Org.), 2003, p. 210). 
O elemento axiológico não é, portanto, nesse paradigma, metajurídico, suprapositivo, como algo incorporado externamente ao direito pela religião, economia, moral, tal como em Dworkin, mas característica imanente ao próprio direito, revelado progressivamente mediante a operação hermenêutica de compreensão e revelação das possibilidades semânticas do texto jurídico.

O contexto é constitutivo do texto jurídico. O texto engloba, pois, o entorno linguístico, como texto puramente verbal, bem como o contexto metalinguístico, o contexto cultural e a mensagem de outros sistemas inseridos na cultura de seu tempo. Não se concebe um sistema de valores paralelo ao direito positivo, mas que o próprio sistema jurídico consubstancia valores, estes, entretanto, determinados caso a caso.

Tomado isoladamente, abstratamente, o texto encontra-se apenas em estado latente, na imanência de sua significação. Efetivamente aplicado, entretanto, o texto, o direito objetivo tem amplo horizonte de sentido; tem uma estrutura aberta a diversos modos de atualização, segundo a determinação da compreensão desse ser aí (Dasein) que questiona pelo seu sentido.

$\mathrm{O}$ aspecto estrutural do texto relaciona-se ao caráter sistemático do direito. "Além de dar clareza e de facilitar o domínio de uma matéria, significa um critério de racionalidade intrínseca, como exigência de cientificidade na interpretação, pela pressuposição lógica da unidade e coesão de sentido”. (LARENZ, 1997, p. 21).

$\mathrm{O}$ aspecto ontológico do texto diz respeito à situacionalidade do intérprete, à sua necessidade de constante atualização de sentido pela reivindicação da compreensão em condições singulares.

Assim, "a noção de texto tensiona o ideal abstrato imanente de unidade interior e adequação do pensamento sistemático com o seu elemento referencial transcendente contrário: o da tendência individualizadora da justiça no caso concreto". (CANARIS, 2002, p. 199).

A norma, então, não é algo diferente do texto, como um resultado da interpretação, mas o próprioato hermenêutico que lhe dá temporalidade pela revelação e atualização de seu sentido.

O preceito deôntico do texto não é isolado em seu sentido, mas diz respeito a uma mediação entre a significação sincrônica dos preceitos jurídicos e a isotopia do contexto de aplicação, ou seja, encontra-se na ação de mediação pela qual a significação virtual, potencial, torna-se concreta, efetiva pela necessidade de um sentido justo para o contexto de aplicação.

De um modo geral, segundo a chamada corrente hermenêutica (continental, filosófica ou hermenêutica dialética), a interpretação não só deve entender-se como uma atividade específica, ou técnica (um método de trabalho), senão também como uma atitude filosófica 
global, como uma modalidade constitutiva do ser humano, como o modo próprio pelo qual o homem entra em contato com o mundo.

Desde este ponto de vista, o que faz possível a compreensão de um texto não é somente a tarefa de análise e recuperação do contexto da obra e do autor, senão a unidade originária e primogênita que funda toda compreensão.

\begin{abstract}
No âmbito continental, a virada hermenêutica deu-se na transição da epistemologia (Schleiermacher e Dilthey) para a ontologia (Heidegger e Gadamer) - de modo de conhecer passou para o modo de ser -, enquanto na filosofia da linguagem a virada foi interna, de uma feição lógico-abstrata (Wittgenstein) para um viés pragmático (Austin, Frege). A virada hermenêutica (hermeneuticturn) retrata e fundamenta a impossibilidade de reduzir a linguagem à perspectiva científico-moderna. Já a virada da filosofia da linguagem consiste numa revisão da semântica tradicional, em que a significação não depende mais da ordenação objetiva, mas a palavra tem sentido pela maneira como é usada, isto é, de acordo com a função determinada que exerce num jogo de linguagem.(ROHDEN, 2003, p. 60).
\end{abstract}

Ademais, todo esse novo movimento hermenêutico representou um rechaço radical às regras com que opera naturalmente nossa mente e uma demonstração definitiva do abismo que separa o reino ideal das verdades e os princípios do ser-conhecer da mecânica empírica da mente humana. Um repelir que, estendido em todas as direções, pode ser perfeitamente rastreado, por exemplo, na resistência às primeiras hermenêuticas de caráter existencialista e psicologista, como as elaboradas por Schleiermacher e Dilthey, e sua reelaboração em claves ontológicas, desvinculadas da psicologia empírica, como as propostas por Heidegger ou Gadamer.

De fato, foi grande o esforço das hermenêuticas de corte ontológico de Heidegger e Gadamer por descontaminar a hermenêutica e a antropologia de qualquer consideração psicológica empírica. Gadamer, por exemplo, está em conflito com a hermenêutica romântica e contra toda forma de hermenêutica psicológica. Já a análise existencialista, levada a cabo por Heidegger, é um perfeito exemplo deste desejo de reinterpretar qualquer traço existencial nos novos termos de uma ontologia do dasein.

É tarefa do Estado e da sociedade a mudança de atitude para que se reescrevam os caminhos da interpretação, da hermenêutica jurídica. Ao interprete cabe dar sentido ao texto segundo as compreensões do mundo em que vive, bem como, reinterpretar as considerações que se transformam com o ciclo histórico da vida.

Os fatos da vida por vezes colidem com o direito, pois aquilo que o legislador queria dizer há anos atrás pode não ser mais aceito no mundo atual. Assim, torna-se importante a invasão da filosofia no campo jurídico, através da linguagem, como caminho para a recepção de novos paradigmas, como quer a hermenêutica filosófica. 


\section{Considerações Finais}

Apresentou-se neste artigo uma reflexão acerca da hermenêutica sob um prisma jurídico e filosófico, passando pelas teorias unilaterais do direito, por aspectos relevantes sobre a linguagem, a interpretação e a hermenêutica, para, ao final, apontar os caminhos traçados pela hermenêutica filosófica contemporânea, buscando uma inovação do processo de interpretação jurídica.

A linguagem, como qualquer outro meio, tem as suas limitações. E talvez a pretensão de garantir a objetividade dos discursos da filosofia e da hermenêutica mediante a elaboração de métodos seja, demasiadamente, pretensiosa ou ingênua ou ambos. Não porque os métodos sejam desnecessários, mas porque a sua elaboração não é objetiva e a sua aplicação não pode garantir a prometida objetividade, especialmente, nas ciências sociais e na filosofia.

Assim, a objetividade do conhecimento científico e da aplicação do direito não pode ser garantida por meio da elaboração de um método adequado para lidar com a linguagem. Então, antes de mais nada, é preciso compreender os limites da própria linguagem, esclarecendo devidamente a sua estrutura, suas características, bem como a origem das indeterminações e obscuridades, que sempre acompanham o seu uso. Somente assim poderemos saber até onde um pensamento metodológico poderá nos conduzir.

Um dos maiores responsáveis por essa convergência foi Wittgenstein, que é um dos filósofos da linguagem mais lidos pela tradição continental, especialmente porque ele propôs em suas obras póstumas conceitos linguísticos que se contrapunham à filosofia analítica tradicional e que abriram espaço para uma espécie de historicização da linguagem.

Em vez de se preocupar apenas com a formalização da linguagem e da garantia de rigor e precisão necessários para uma linguagem científica, Wittgenstein foi o grande responsável pelo nascimento de uma filosofia da linguagem ordinária, em que a busca não era a de estabelecer uma linguagem purificada, mas de compreender o modo como as linguagens naturais efetivamente funcionam.

O autor rompeu com a noção cientificista de que a perfeição linguística estava no rigor e na precisão, e afirmou a existência de uma pluralidade de jogos linguísticos, cada qual com suas regras e elementos.

Contrapondo-se à ideia de que a linguagem natural era inadequada ao conhecimento, Wittgenstein passou a defender que faltava ao neopositivismo lógico uma compreensão filosófica adequada dos mecanismos que regem as linguagens ordinárias: enquanto estes 
estudos se limitavam aos planos sintáticos $e$ semânticos, uma compreensão das linguagens ordinárias dependia de uma análise pragmática.

No campo da hermenêutica, o maior protagonista nessa aproximação entre historicidade e linguagem foi Gadamer, que operou uma espécie de releitura linguística dos conceitos hermenêuticos propostos por Heidegger no campo da ontologia. Assim, mesmo que se tenha inspirado explicitamente na hermenêutica da faticidade heideggeriana, foi de Gadamer o grande esforço no sentido de levar essa renovada preocupação hermenêutica ao campo da interpretação dos objetos culturais.

A hermenêutica clássica propõe a linguagem como mecanismo de busca de uma verdade já contida na lei, desinteressada da realidade trazida pelo intérprete. A eleição de uma hermenêutica acolhedora, cuja linguagem é tida como razão de existir do processo interpretativo, parece ser acertada, uma vez que busca a verdade por meio das précompreensões que o intérprete desde sempre possui do mundo. Esses prejulgamentos se perfazem pela linguagem e ampliam o movimento das relações sociais.

Em outras palavras, urge um novo despertar da consciência hermenêutica dos juristas, uma reinvenção ou construção conjunta de alternativas metodológicas reais e factíveis, compatível com a dimensão, essencialmente, humana da tarefa de interpretar, justificar e aplicar o direito.

Enfim, um novo modelo hermenêutico-interpretativo que, mantendo uma relação mais amigável com o funcionamento do cérebro, nos proporcione instrumentos mais frutíferos e fascinantes de cultivar o direito do que essa espécie de hermenêutica jurídica 'no vazio' em que todos nos acostumamos a comprazer-nos nos velhos tempos.

$\mathrm{O}$ avanço adequadamente articulado entre a ontolinguística da teoria hermenêutica e o pragmatismo estrutural da linguística possibilita uma aplicação jurídica pela qual a leitura imprime densidade normativa a princípios e valores jurídicos, sem descambar para a unilateralidade própria da axiologia, do realismo ou mesmo do decisionismo normativista.

Assim, torna-se imperiosa a defesa de uma ontologia jurídica, que vê o direito como um objeto em permanente construção e reconstrução no processo de sua interpretação e aplicação.

A concreção do Direito, portanto, é também um momento ontológico-hermenêutico. Não se trata de interpretar o sentido de uma lei, mas as possibilidades desta lei de fazer justiça ao caso concreto. Este deve ser o objetivo do aplicador que, para consegui-lo tem que compreender a si mesmo. 


\section{Referências}

BOBBIO, Norberto. O positivismo jurídico: lições de filosofia do direito. Tradução de Márcio Pugliesi. São Paulo: Ícone, 1995.

CANARIS, Claus-Wilhelm. Pensamento sistemático e conceito de sistema na ciência do direito. 3. ed. Lisboa: Gulbenkian, 2002.

COELHO, Inocêncio Mártires. Interpretação Constitucional. 2. ed. Porto Alegre: Fabris, 2003.

DINIZ, Márcio Augusto de Vasconcelos. Constituição e hermenêutica constitucional. Belo Horizonte: Mandamentos, 1998.

FERRARA, Francesco. Interpretação e aplicação das leis. 4. ed. Coimbra: Arménio Amado, 1987.

GADAMER, Hans-Georg. Verdade e método. 5.ed. Petrópolis: Vozes, 2003.v. 1. HABERMAS, Jurgen. Consciência moral e agir comunicativo. Rio de Janeiro: Tempo Brasileiro, 1989.

. A ética da discussão e a questão da verdade. Tradução de Marcelo Brandão Cipolla. São Paulo: Martins Fontes, 2004.

HART, Herbert L. A. O conceito de direito. Tradução de A. Ribeiro Mendes. 3. ed. Lisboa: Gulbenkian, 2001.

HEIDEGGER, Martin. Ser e tempo. 5. ed. Petrópolis: Vozes, 1995.

HESSE, Konrad. Elementos de direito constitucional da República Federal da Alemanha. Tradução de Luís A. Heck. Porto Alegre: Fabris, 1998.

LARENZ, Karl. Metodologia da ciência do direito. 3. ed. Lisboa: Gulbenkian, 1997.

MAGALHÃES, Theresa Calvet de. A reflexão de Ricoeur sobre o justo. Síntese: Revista de Filosofia, v. 29, n. 93, 2002.

MASCARO, Alysson Leandro. Filosofia do Direito. São Paulo: Atlas, 2013.

MAXIMILIANO, Carlos. Hermenêutica e aplicação do direito. 18. ed. Rio de Janeiro: Revista Forense, 1999.

PALMER, Richard E. Hermenêutica. Tradução de Maria Luísa R. Ferreira. Lisboa: Edições 70, 1986.

PEREIRA, Rodolfo Viana. Hermenêutica filosófica e constitucional. Belo Horizonte: Del Rey, 2001.

PUGLIESI, Márcio. Por uma teoria do direito: aspectos microssistêmicos. São Paulo: RCS, 2005 . 
ROHDEN, Luiz. Hermenêutica filosófica. São Leopoldo: Unisinos, 2003.

SALDANHA, Nelson. Ordem e hermenêutica. 2. ed. Rio de Janeiro: Renovar. 2003.

SALGADO, Joaquim Carlos. A ideia de justiça no mundo contemporâneo. Belo Horizonte: Del Rey, 2006.

Princípios hermenêuticos dos direitos fundamentais. Apud MERLE, Jean C.;

MOREIRA, Luis (Org.). Direito e legitimidade. São Paulo: Landy, 2003.

SILVA, Christine Oliveira Peter da. Hermenêutica de direitos fundamentais: uma proposta constitucionalmente adequada. Brasília, 2001. 267 f. Dissertação (Mestrado em Direito e Estado) - Faculdade de Direito, Universidade de Brasília.

STRECK, Lênio Luiz. Hermenêutica jurídica e(m) crise: uma exploração hermenêutica da construção do Direito. 2. ed. Porto Alegre: Livraria do Advogado, 2000. Verdade e consenso: Constituição, hermenêutica e teorias discursivas. Da possibilidade à necessidade de respostas corretas no direito. Rio de Janeiro: Lumem Juris, 2007.

WARAT, Luis Alberto. Epistemologia e ensino do direito: o sonho acabou. Florianópolis: Fundação Boiteux, 2004. v. II.

Introdução geral ao direito - interpretação da lei: temas para uma reformulação.

Porto Alegre: Sergio Antonio Fabris, 1994. v. 1.

WITTGENSTEIN, Ludwig. Investigações filosóficas. Trad. Marcos G. Montagroli; rev. da trad. Apresentação Emmanuel Carneiro Leão. 4. ed. Petrópolis: Vozes, 2005.

\section{Sobre os autores:}

Clóvis Gorczevski é advogado, doutor em direito (Universidad de Burgos, 2001), pós-doutor em direito (CAPES - Universidad de Sevilla, 2007), pós-doutor (CAPES - Fundación Carolina - Universidad de La Laguna, 2010). Professor-pesquisador do Programa de PPGD Mestrado/Doutorado da Universidade de Santa Cruz do Sul - UNISC. Endereço eletrônico: clovisg@unisc.br

Grazieli Schuch Mayer é advogada, Assessora Jurídica Municipal. Especialista em Direito Processual Civil e Mestranda em Direito pela UNISC com bolsa CAPES. Endereço eletrônico: gs.mayer@bol.com.br 